\title{
To Evaluate The Effect Of Addition Of Dexmedetomidine to Ropivacaine in Transversus Abdominis Plane Block on Post- Operative Analgesia After Caesarean Section- A Randomized Double Blind Study.
}

\author{
Krishna Pratap Mall', Sujeet Rai', Richa Gangwar ${ }^{3}$ \\ ${ }^{1}$ Associate professor, Department of Anaesthesiology \& Critical Care TS Mishra Medical College, Lucknow, Uttar Pradesh, ${ }^{2}$ Associate Professor, \\ Department of Anaesthesiology \& Critical Care, Dr. RML Institute of Medical Sciences, Lucknow, Uttar Pradesh, ${ }^{3}$ Associate Professor, Department of \\ obstetrics and gynecology Autonomous state medical college, Bahraich, Uttar Pradesh.
}

Abstract

Background: Studies have demonstrated the efficacy of Transverses abdomen plane (TAP) block as a component of multimodal postoperative analgesia after cesarean section. The aim of the present study was to compare the efficacy of combination of dexmedetomidine and ropivacaine to ropivacaine alone for Transversus abdominis plane (TAP) block as post-operative analgesic after lower segment cesarean section (LSCS). Subjects and Methods: A randomized double blind, prospective study was conducted on 100 ASA grade I and II pregnant patients undergoing LSCS under spinal anesthesia. They were randomly divided into two groups, group I ( $\mathrm{n}=50$ ) received $20 \mathrm{ml}$ of ropivacaine $0.25 \%$ and $2 \mathrm{ml}$ of normal saline while group II $(\mathrm{n}=50)$ received $0.5 \mathrm{mcg} / \mathrm{kg}$ dexmedetomidine dissolved in $2 \mathrm{ml}$ of normal saline and $20 \mathrm{ml}$ of ropivacaine $0.25 \%$ as bilateral TAP block at the end of surgery. The total duration of effective analgesia was recorded as primary outcome and secondary outcomes were pain score, total requirement of analgesics in the first $24 \mathrm{hrs}$ postoperatively and side effects. Results: The time for first analgesic dose was longer in group I than group II (282.58 vs $192.2 \mathrm{~min}, \mathrm{p}<0.05)$ and total dose of Tramadol used in the first 24 hrs was less among patients in group II when compared with those in group I (72 vs. $98 \mathrm{mg}, \mathrm{p}<0.05$ ). Pain was significantly reduced at all postoperative points for the first 6 hrs in group II compared with group I ( $\mathrm{p}<0.05)$. Changes in systolic, diastolic and mean arterial pressure and heart rate were statistically insignificant in both groups. There was no statistically significant difference in the incidence of side effects in both groups. Conclusion: In conclusion, this study shows that addition of dexmedetomidine to ropivacaine for TAP block after cesarean section, achieves better analgesia and provides longer duration of pain control post-operatively without any major side-effects.

Keywords: Cesarean section, Ropivacaine, Dexmedetomidine, TAP Block, Spinal Anaesthesia.

Corresponding Author: Dr. Richa Gangwar, Associate Professor, Department of obstetrics and gynecology, Autonomous state medical college, Bahraich, Uttar Pradesh.

Received: July 2019

Accepted: August 2019

\section{Introduction}

Transversus abdominis plane (TAP) block is a regional analgesia technique that blocks abdominal wall neural afferents between T6 and L1 and thus can relieve somatic pain associated with an abdominal incision. ${ }^{\mathrm{i}, \mathrm{i}}$ There is considerable potential for TAP block to comprise an effective component of a multimodal regimen for post lower segment cesarean section (LSCS) analgesia. TAP in cesarean section has been given with local anesthetics like bupivacaine and ropivacaine with a limited duration of action. ${ }^{\text {iii }}$ Additives to local anesthetics like opioids, ketamine and $\alpha 2$ agonists like clonidine and dexmedetomidine have been successfully used in peripheral nerve blocks and field blocks to increase the duration of postoperative analgesia. ${ }^{\text {iv }}$ In view of the foregoing we planned to carry out a prospective, double-blind, randomized study with aim as given below.

\begin{abstract}
Aim of the study
The primary aim of this study was to compare the efficacy of the combination of dexmedetomidine and ropivacaine to ropivacaine alone in TAP block after $\mathrm{C}$-section in terms of duration of effective analgesia. Secondary aims included pain score, total requirement of analgesics in the first $24 \mathrm{hrs}$ postoperatively and side effects.
\end{abstract}

\section{Subjects and Methods}

After approval from the scientific and ethical committee of our institution, written informed consent was obtained 
from100 adult patients; American Society of Anesthesiologists physical status I and II patients, posted for elective caesarean section under spinal anaesthesia (SA) were recruited.

Patients who refused to participate in the study, with known allergy to local anaesthetic agents, who received any nonsteroidal anti-inflammatory drugs or opioids 48 hours prior to surgery, failed block or patients with any contraindication for spinal anaesthesia, unable to communicate in either English or Hindi language or those who did not tolerate spinal anaesthesia well and had to be converted to general anaesthesia for cesarean section were excluded from the study.

They were randomly assigned to one of the two groups group I and II. Randomization was performed using a computer generated program to allocate patients to the two groups using the method of random number. Group allocation was concealed in serially numbered sealed, opaque envelopes that were opened in the operating theatre just prior to the administration of spinal anaesthesia. Medications $(22 \mathrm{ml})$ were prepared by an anesthesiologist in a $50 \mathrm{ml}$ syringe labeled as "study drug" who was not involved in the study to maintain blinding. The patient and the anesthesiology resident administering the TAP block and involved in data collection were also blinded to group assignment. The code was broken after the completion of the study and statistical analysis.

During the pre-operative anesthetic assessment of patients, visual analog scale (VAS) for pain assessment was explained to the patients with number from 0 to $10 \mathrm{~cm}$, with 0 meaning no pain and 10 meaning the worst pain before administering the block.

Patients were monitored by non-invasive blood pressure, electrocardiogram (E.C.G), pulse oximetry and temperature. Spinal anesthesia was administered in all patients in sitting position with 25gauge Quincke needle at the L3-L4 inter space and $2 \mathrm{ml}$ of $0.5 \%$ bupivacaine (heavy) was given after obtaining free flow of CSF.

Group I $(n=50)$ patients received TAP block on each side with $20 \mathrm{ml}$ of ropivacaine $0.25 \%$ and $2 \mathrm{ml}$ of normal saline., Group II $(n=50))$ received TAP block on each side with 22 $\mathrm{ml}$ of study medication, in which dexmedetomidine 0.5 $\mathrm{mcg} / \mathrm{kg}$ was dissolved in $2 \mathrm{ml}$ of normal saline and added to $20 \mathrm{ml}$ of ropivacaine $0.25 \%$.

All patients of study groups I \& II received TAP block using landmark technique as described by McDonnell et al ${ }^{\mathrm{v}}$. The assessment of presence and intensity of pain (both on rest and on passive flexion of hip and knee), nausea, vomiting, and sedation was done immediately after transfer to PACU ( 0 hour) and at 1,4, 8, 16 and 24, hour after surgery. The intensity of pain was assessed on VAS Score $0-10(0=$ no pain, to $10=$ worst pain). Level of sedation was assessed as a sedation score of $0-3$, where $0=$ awake and alert, $1=$ quietly awake, 2 = asleep but easily arousal, $3=$ deep sleep, but responding to painful stimulus. Patients were labeled to be sedated if score was $>2$. Inj. Ondansetron $4 \mathrm{mg}$ intravenously was given if patients complained of persistent nausea or vomited.

After the surgery, all observations were made by an independent observer who was unaware of group allocation. The duration of effective postoperative analgesia, defined as the time (in hours) from the giving of the TAP block to the time to the first analgesic request in the postoperative period was recorded. Intravenous tramadol was given as rescue analgesia for postoperative pain relief if pain score was $>3$ or when it was requested by the patients; total tramadol consumption in $24 \mathrm{hrs}$ was recorded. The pain scores (VAS) with and without movement, sedation score and side effects were also noted at 1, 4, 8, 16 and 24 hours postoperatively.

\section{Outcome}

The primary outcome was the duration of postoperative analgesia and the total requirement of analgesics (Inj. Tramadol) in the first $24 \mathrm{hrs}$ postoperatively. Secondary outcomes were, pain score variation and possible dexmedetomidine side effects (dryness of mouth, sedation, hypotension, and bradycardia).

Demographic variables were analyzed using Fisher's exact test, repeated measurements recorded by repeated measures unpaired $t$ test if normally distributed and nominal or ordinal variables by Chi-square test. Results were expressed by standard methods i.e. as mean \pm standard deviation. Chisquare test was applied for physical status. Statistical analysis was performed by SPSS (version 20.0). P-value was considered significant if $<0.05$ and highly significant if $<0.001$.

\section{Results}

A total of 100 patients who fulfilled the criteria were randomized for this study. Four patients were excluded because of a second surgical intervention in the immediate post-operative period. A total of 47 patients in group I and 49 patients in II group were included in the study. The two groups were not different in respect of demographic and other operative characteristics except for duration of surgery as shown in table 1 . The time to the first analgesic request (Duration of analgesia) in the postoperative period was statistically higher in group II as compared to group I (282.6 \pm 9.4 vs. $192.2 \pm 7.5 \mathrm{~min}$.), $P<0.001$ ) as shown in table 2 and figure 1 . The cumulative tramadol consumption during first $24 \mathrm{hrs}$ after surgery was significantly reduced in the study group II in comparison to group I $(72 \pm 26.5$ vs. $97 \pm 35.3$ $\mathrm{mg}), \mathrm{P}<0.001$ ) as shown in table 2 figure 2 . The patients of group I reported statistically significant higher pain scores in first 8 hours after the surgery as compared to group II as assessed by Mean Visual Analog Score (VAS Group I and group II $\mathrm{p}<0.05$ ) as shown in table 3 and figure 3.

The patients of Group II reported significantly higher sedation score during first hour of the post-operative period as compared to group I $(1.68 \pm 0.57$ vs. $1.12 \pm 0.52, \mathrm{P}<0.001)$ but after 1 hour, there was no difference in sedation score of the patients between the two groups as shown in table 4 figure 4. Postoperative nausea and vomiting (PONV) were more in the group II but not statistically significant, total 12 (24\%) patients from both the groups complained of nausea and/vomiting and required ondansetron medication as shown in table 5. Two (4\%) patients complained of headache in group I \& one (2\%) patient in group II, hematoma in the transversus abdominis muscle was reported in $1(2 \%)$ case from group I and in $3(6 \%)$ cases from group II and mouth 
dryness was reported in a single case from group II.

Table 1: Demographic and clinical details of two groups

\begin{tabular}{|l|l|l|l|l|l|}
\hline Variable & \multicolumn{2}{|l|}{$\begin{array}{l}\text { Group I } \\
\text { (Ropivacaine) }\end{array}$} & $\begin{array}{l}\text { Group II } \\
\text { (Ropivacaine+ } \\
\text { Dexmedetomidine) }\end{array}$ & \multirow{2}{*}{ P-value } \\
\cline { 2 - 5 } & Mean & SD & Mean & SD & \\
\hline Age(Year) & 26.8 & 4.32 & 27.2 & 6.08 & 0.7053 \\
\hline Weight(Kg) & 53.7 & 3.81 & 54.2 & 4.24 & 0.5365 \\
\hline Height(cm) & 153.2 & 5.23 & 154.8 & 6.16 & 0.1646 \\
\hline $\begin{array}{l}\text { Duration of } \\
\text { surgery } \\
\text { (min) }\end{array}$ & 41.8 & 4.71 & 43.7 & 4.82 & $0.0490^{*}$ \\
\hline
\end{tabular}

$*_{p}<0.05$ value is indicative of significant difference between the means of Group I and II.

Table 2: Time to first analgesic request (Duration of analgesia) and $24 \mathrm{hr}$ Tramadol consumption in both groups.

\begin{tabular}{|l|l|l|l|l|l|}
\hline Variable & \multicolumn{2}{|l|}{$\begin{array}{l}\text { Group I } \\
\text { (Ropivacaine) }\end{array}$} & $\begin{array}{l}\text { Group II } \\
\text { (Ropivacaine+ } \\
\text { Dexmedetomidine) }\end{array}$ & \multirow{2}{*}{ p-value } \\
\cline { 2 - 5 } & Mean & SD & Mean & SD & \\
\hline $\begin{array}{l}\text { Time to first } \\
\text { analgesic } \\
\text { request } \\
\text { [Tramadol] } \\
\text { (Duration of } \\
\text { analgesia) } \\
\text { (in min) }\end{array}$ & 192.2 & 7.5 & 282.6 & 9.4 & $<0.001^{*}$ \\
\hline $\begin{array}{l}\text { Total } \\
\text { Tramadol } \\
\text { consumption } \\
\text { (in mg) in 24 } \\
\text { hours }\end{array}$ & 97.0 & 35.3 & 72.0 & 26.5 & $<0.001^{*}$ \\
\hline
\end{tabular}

Table 3: Pain score (VAS) after the TAP block in both the groups.

\begin{tabular}{|l|l|l|l|l|l|} 
groups. \\
\begin{tabular}{|l|l|l|l|} 
Post-op \\
period
\end{tabular} & \multicolumn{2}{|l|}{$\begin{array}{l}\text { Group I } \\
\text { (Ropivacaine) }\end{array}$} & $\begin{array}{l}\text { Group II } \\
\text { (Ropivacaine+ } \\
\text { Dexmedetomidine) }\end{array}$ & \multirow{2}{*}{$\begin{array}{l}\text { v- } \\
\text { value }\end{array}$} \\
\cline { 2 - 5 } & Mean & SD & Mean & SD & \\
\hline $\begin{array}{l}\text { Immediate } \\
\text { post op. }\end{array}$ & 0 & 0 & 0 & 0 & - \\
\hline $\mathbf{1}$ hour & 0 & 0 & 0 & 0 & - \\
\hline $\mathbf{4}$ hour & 2.30 & 1.22 & 1.62 & 1.15 & $0.005^{*}$ \\
\hline $\mathbf{6}$ hour & 2.60 & 1.17 & 1.90 & 1.07 & $0.002^{*}$ \\
\hline $\mathbf{8}$ hour & 3.10 & 1.61 & 2.10 & 1.53 & $0.002^{*}$ \\
\hline $\mathbf{1 6}$ hour & 3.40 & 1.67 & 3.12 & 1.52 & 0.383 \\
\hline $\mathbf{2 4}$ hour & 2.40 & 1.39 & 2.60 & 1.64 & 0.512 \\
\hline
\end{tabular}

\begin{tabular}{l}
\hline \begin{tabular}{|l|l|l|l|l|l|}
\hline $\begin{array}{l}\text { Table 4: Sedation score in post-op period in both the groups. } \\
\text { period }\end{array}$ & $\begin{array}{l}\text { Group I } \\
\text { (Ropivacaine) }\end{array}$ & $\begin{array}{l}\text { Group II } \\
\text { (Ropivacaine+ } \\
\text { Dexmedetomidine) }\end{array}$ & p-value \\
\cline { 2 - 5 } & Mean & SD & Mean & SD & \\
\hline $\mathbf{1}$ hour & 1.12 & 0.52 & 1.68 & 0.57 & $<0.001^{*}$ \\
\hline $\mathbf{4}$ hour & 1.07 & 0.23 & 1.12 & 0.31 & 0.3620 \\
\hline $\mathbf{8}$ hour & 0.99 & 0.14 & 1.04 & 0.21 & 0.1644 \\
\hline $\mathbf{1 6}$ hour & 0.94 & 0.11 & 0.98 & 0.13 & 0.0999 \\
\hline $\mathbf{2 4}$ hour & 0.88 & 0.10 & 0.92 & 0.11 & 0.0600 \\
& & & & & \\
\hline
\end{tabular}
\end{tabular}

${ }^{*} \mathrm{p}<0.05$ value is indicative of significant difference between the means of Group I and II.

Table 5: Proportion of side effects observed in both groups

\begin{tabular}{|l|l|l|l|}
\hline Side effects & $\begin{array}{l}\text { Group I } \\
\text { (Ropivacaine) } \\
\text { N=50 }\end{array}$ & $\begin{array}{l}\text { Group II } \\
\text { (Ropivacaine+ } \\
\text { Dexmedetomidine) } \\
\text { N=50 }\end{array}$ & p-value \\
\hline PONV & $5(10 \%)$ & $7(16 \%)$ & $>0.05$ \\
\hline Headache & $2(4 \%)$ & $1(2 \%)$ & $>0.05$ \\
\hline $\begin{array}{l}\text { Dryness of } \\
\text { mouth }\end{array}$ & $1(2 \%) \mathrm{s}$ & $1(2 \%)$ & $>0.05$ \\
\hline Hematoma & $1(2 \%)$ & $3(6 \%)$ & $>0.05$ \\
\hline & & & \\
\hline p $<0.05$ value is indicative of significant difference between the means of Group I and II.
\end{tabular}

\section{Discussion}

In the present study, the prominent finding is that addition of dexmedetomidine to ropivacaine for TAP block provides prolonged post-operative analgesia and better pain control than ropivacaine alone. The duration of analgesia was longer, VAS was lower and the needs for rescue tramadol doses were lesser when dexmedetomidine was added to ropivacaine. The explanation of the prolonged duration of analgesic effect after TAP block may be related to the fact that transversus abdominis plane is relatively poorly vascularized, and therefore drug clearance may be slow by reduction of absorption in to the blood stream. ${ }^{[6]}$

Ropivacaine with its efficacy, lower propensity for motor block and reduced potential for cardiac and central nervous system toxicity, appears to be an important option for regional anesthesia and management of postoperative pain ${ }^{[7]}$ Recently, adjuvant medications were added to local anaesthetics to prolong the effect of TAP block. ${ }^{[8]}$ Dexmedetomidine is a selective alpha $2\left(\alpha_{-2}\right)$ adrenergic agonist with both analgesic and sedative properties. ${ }^{[9]}$ Studies done by Kanazi GE et $\mathrm{al}^{[10]}$ and Jain $\mathrm{D}$ et $\mathrm{al}^{11}$ have found that the addition of dexmedetomidine to to local anaesthetics in central neuraxial blocks and in peripheral nerve blockades in human was a safe and effective way to potentiate the effect and reduce the analgesic requirement . Carney $\mathbf{J}$ et al ${ }^{[12]}$ have 
shown that the median time to first request for morphine was significantly longer in the TAP block group as compared to control group in patients undergoing total abdominal hysterectomy (TAH). Marhofer D et $\mathrm{al}^{13}$ have reported that the addition of dexmedetomidine to ropivacaine in various types of peripheral nerve blocks resulted in prolongation of analgesic effect, same as we observed as the variation in mean VAS between the two groups was statistically highly significant in first 6 hours post-operatively. Almarakbi WA et $\mathrm{al}^{14}$ in their study also reported visual analog scores were significantly lower in dexmedetomidine with bupivacaine group in the first $8 \mathrm{~h}$ post-operatively when compared with bupivacaine group postoperatively which was in agreement with our findings. The inter-group VAS was compared at different time points after surgery, thus strengthening the objective assessment of the quality of analgesia. Dexmedetomidine is associated with side effects such as sedation, bradycardia and hypotension at higher doses but none were noted in present study as maybe due to the low dose of drug and its slow absorption from the TAP block. Masuki et al suggested that dexmedetomidine induces vasoconstriction through an action on $\alpha 2$ adrenoceptors in the human forearm possibly also causing vasoconstriction around the site of injection, delaying the absorption of local anesthetic and hence prolonging the effect. ${ }^{15}$ These major sedative and antinociceptive effects of dexmedetomidine are attributable to its stimulation of the $\alpha_{2}$ adrenoceptors in the locus coeruleus. The use of dexmedetomidine was associated with a decrease in heart rate and blood pressure as reported in a study by Al-Ghanem et al. ${ }^{[16]}$

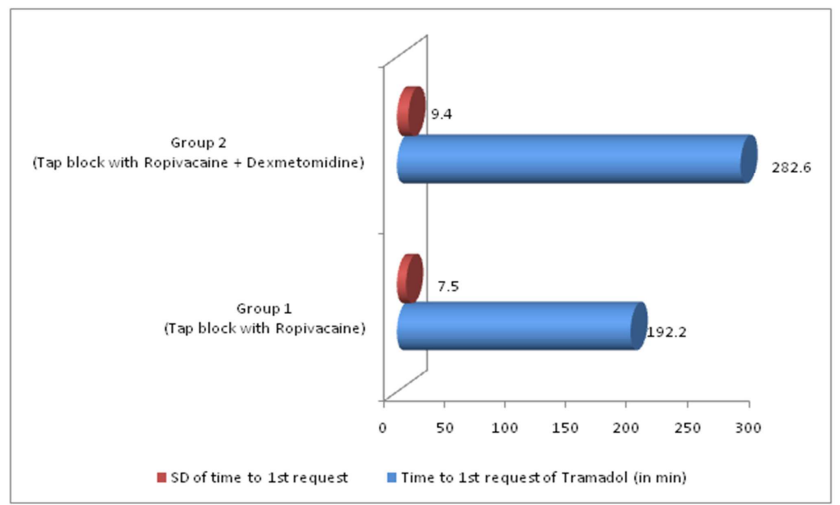

Figure 1: Time to first request of Tramadol (Duration of analgesia in min.)

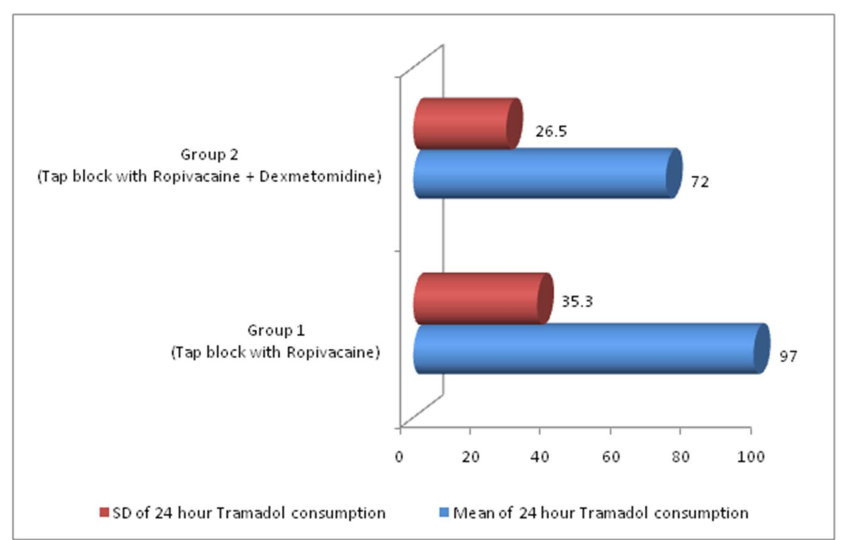

Figure 2: 24 hour Tramadol consumption(in mg)

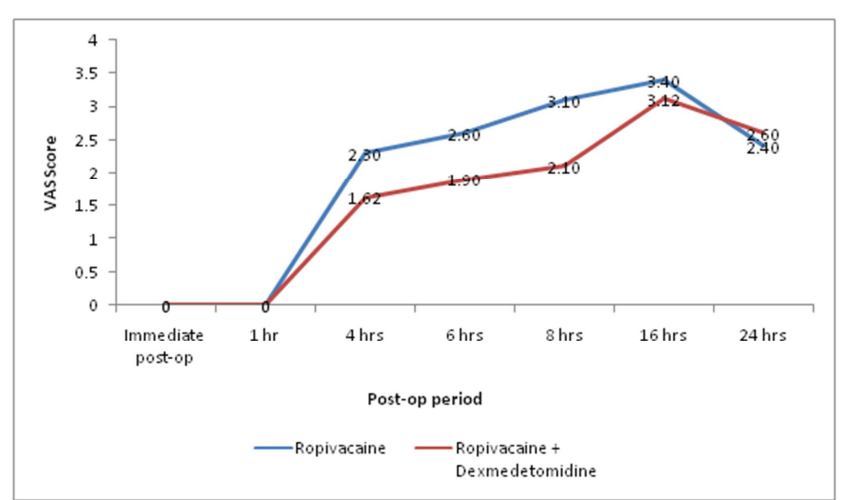

Figure 3 : Visual Analogue Score in post-op period

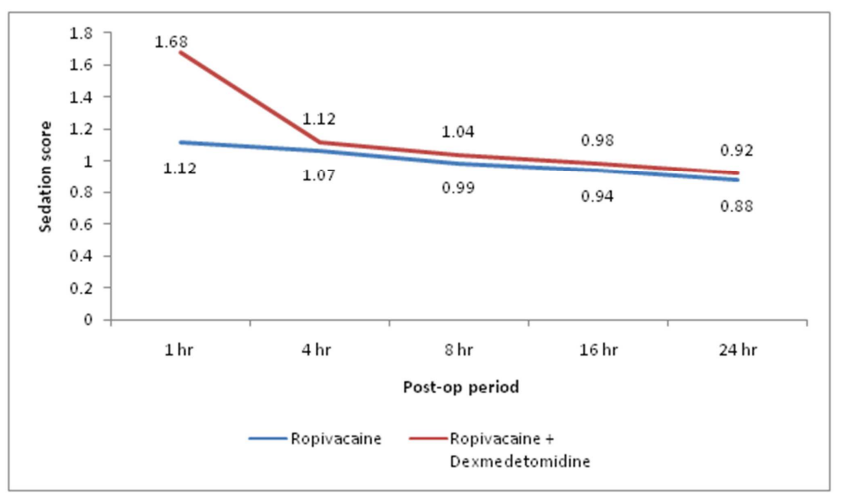

Figure 4: Sedation Scores in post-op period

In the present study side-effects observed were PONV, headache and dryness of mouth. PONV was the most prevalent i.e $10 \%$ and $14 \%$ in both the groups, followed by headache $4 \%$ and $2 \%$, there was no significant difference between all the observed side effects. This could be due to the combination of $\alpha_{2}$ agonists with ropivacaine, even though ropivacaine has been shown to be a better drug in terms of cardiovascular and hemodynamic control. ${ }^{[17]}$ We also did not observe any hemodynamic side effects in our study.

Hematoma was observed as a side effect of TAP block in both groups. In our study TAP block was performed as tactile blind procedure and as we did not use ultrasound to visualize the anatomy, we could not ensure cent percent correct placement of the block, it might be possible that a portion of the block were placed incorrectly either superficially or intraperitoneally. ${ }^{[18]}$

Limitation of this study is, firstly lack of proper assessment of TAP block as it was given following the induction of spinal anaesthesia, but we depend upon the skills of investigators for proper placement of drug in the correct plane. An ultrasound guided TAP blocks would have been a more appropriate technique. Second limitation was the inability to assess dexmedetomidine plasma concentration to determine whether its action was related to systemic absorption or pure local effect but as only the analgesia seems to be prolonged without any drug related side effect we assume that the effect was completely regional.

Third, the study was not large enough to assess safety. There is a risk of inadvertent peritoneal puncture with this block, however small. We, however, have not encountered this complication in the TAP blocks we now routinely perform. 
The use of ultrasound to confirm needle position further reduces the risk of this complication, besides increasing the success rate and efficacy of the block. But many centers, including ours, still do not have access to this facility.

Based on the aforesaid findings of our study, it may be concluded that the addition of dexmedetomidine to ropivacaine in TAP block enhances the duration of anesthesia and provides better pain control post-operatively without any major side-effects. Further studies will be required to find the safe as well as effective dose of dexmedetomidine that might lead to further prolongation of analgesia.

\section{Conclusion}

In conclusion, this study shows that addition of dexmedetomidine to ropivacaine for TAP block after cesarean section, achieves better analgesia and provides longer duration of pain control post-operatively without any major side-effects.

\section{References}

1. Rafi AN. Abdominal field block: A new approach via the lumbar triangle. Anesthesia 2001;56:1024-6.

2. McDonnell JG, O\&\#39;Donnell B, Curley G, Heffernan A, Power C Laffey JG. The analgesic efficacy of transversus abdominis plane block after abdominal surgery: A prospective randomized controlled trial. Anesthesia analgesia 2007;104:193-7.

3. Abdallah FW, Halpern SH, Margarido CB.Transversus abdominis plane block for postoperative analgesia after Caesarean delivery performed under spinal anaesthesia? A systematic review and metaanalysis. Br J Anaesth. 2012;109:679-87.

4. Singh R, Kumar N, Jain A, Joy S. Addition of clonidine to bupivacaine in transversus abdominis plane block prolongs postoperative analgesia after cesarean section. Journal of Anaesthesiology and Clinical Pharmacology. 2016; 32(4):501-504.

5. McDonnell JG, Curley G, Carney J, Benton A, Costello J, Maharaj $\mathrm{CH}$, et al. The analgesic efficacy of transversus abdominis plane block after cesarean delivery: A randomized controlled trial.
Anesthesia Analgesia 2008;106:186-91.

6. Velchev V, Malamov K. The analgesic efficacy of transversus abdominis plane (TAP) block. Khirurgiia (Sofiia).2010; 1: 15-18.

7. Kuthiala G, Chaudhary G. Ropivacaine: A review of its pharmacology and clinical use. Indian J Anaesth. 2011;55:104-10.

8. Ammar AS, Mahmoud KM. Effect of adding dexamethasone to bupivacaine on transversus abdominis plane block for abdominal hysterectomy: A prospective randomized controlled trial. Saudi J Anaesth.2012;6:229-33.

9. Coursin DB, Coursin DB, Maccioli GA. Dexmedetomidine- Current Opinion in Critical Care. 2001;7:221-6.

10. Kanazi GE, Aouad MT, Jabbour-Khoury SI, Al Jazzar MD, Alameddine MM, Al-Yaman R, et al. Effect of low-dose dexmedetomidine or clonidine on the characteristics of bupivacaine spinal block. Acta Anaesthesiol Scand. 2006;50:222-7.

11. Jain D, Khan RM, Kumar D, Kumar N. Perioperative effect of epidural dexmedetomidine with intrathecal bupivacaine on haemodynamic parameters and quality of analgesia. South African J. Anaesth Analg. 2012;18:105-9.

12. Carney J, McDonell JG, Ochana A, Bhinder R, laffey JG. The transversus abdominis plane block provides effective Post operative analgesia in patient undergoing total abdominal hysterectomy. Anesth Analg 2008;107: 2056-2060.

13. Marhofer D, Kettner SC, Marhofer S, Weber M, Zeitlinger M. Dexmedetomidine as an adjuvant to ropivacaine prolongs peripheral nerve block: A volunteer study. Br. J. Anaesth. 2012;15:438-42.

14. Almarakbi WA, Kaki AM. Addition of dexmedetomidine to bupivacaine in transversus abdominis plane block potentiates postoperative pain relief among abdominal hysterectomy patients: A prospective randomized controlled trial.Saudi J Anaesth. 2014 Apr;8(2):161-6.

15. Masuki S, Dinenno FA, Joyner MJ, Eisenach JH. Selective alpha2adrenergic properties of dexmedetomidine over clonidine in the human forearm. J Appl Physiol 2005;99:587-92.

16. Al-Ghanem SM, Massad IM, Al-Mustafa MM, Al-Zaben KR, Qudaisat IY, Qatawneh AM, et al. Effect of adding dexmedetomidine versus fentanyl to intrathecal bupivacine on spinal block characteristics in gynaecological procedures - A double blind controlled study. American J of Applied Sciences 2009;6:882-7

17. Yamashita A, Matsumoto M, Matsumoto S, Itoh M, Kawai K, Sakabe T. A comparison of the neurotoxic effects on the spinal cord of tetracaine, lidocaine, bupivacaine, and ropivacaine administered intrathecally in rabbits. AnesthAnalg 2003;97:512-9.

18. Jankovic Z, Ahmed N, Ravishankar N, Archer F. Transversusabdominis plane block: how safe is it? Anesth Analg 2008; 107: 1758-1759.

Copyright: () the author(s), publisher. Academia Anesthesiologica International is an Official Publication of "Society for Health Care \& Research Development". It is an open-access article distributed under the terms of the Creative Commons Attribution Non-Commercial License, which permits unrestricted non-commercial use, distribution, and reproduction in any medium, provided the original work is properly cited.

How to cite this article: Mall KP, Rai S, Gangwar R.To Evaluate The Effect Of Addition Of Dexmedetomidine to Ropivacaine in Transversus Abdominis Plane Block on Post-Operative Analgesia After Caesarean Section - A Randomized Double Blind Study. Acad. Anesthesiol. Int. 2019;4(2):131-135.

DOI: dx.doi.org/10.21276/aan.2019.4.2.31

Source of Support: Nil, Conflict of Interest: None declared. 